\title{
ARQUIVOS DO TERROR E STRONISMO: MEMÓRIA, HISTÓRIA E LUTO
}

\begin{abstract}
Porque los policías nos prohibieron a los vecinos para que nos hablen, estuve ahí sola mi hijo nació como un animal con el brazo fracturado y muerto, y hasta ahora a consecuencia de eso no me quede más estoy enferma y soy todo eso fue lo que pace en ese tiempo. Mi hijo murió ahora yo no estoy más bien no se que va a pasar de mí, también nos robo todo nos amenazaba de muerte y a mi hijo de 4 años le agarraba y le tiraban en la cama con fuerza, porque ellos querían saber donde estaba Victoriano Centurión pasamos muchos maltratos a causas de eso passamos. ${ }^{I}$
\end{abstract}

\section{Anna Flávia Arruda Lanna Barreto²}

\section{Resumo}

O objetivo deste artigo é analisar a importância dos Arquivos do Terror, localizado no Centro de Documentação e Arquivo para a Defesa dos Direitos Humanos (CDyA) da Corte Suprema de Justiça do Paraguai, no conhecimento da história da ditadura paraguaia do general Alfredo Stroessner e de casos de violações dos direitos humanos de mulheres e crianças, vitimadas pelo arbítrio e intolerância do Estado. A metodologia adotada foi a pesquisa bibliográfica e a pesquisa documental, baseadas no cruzamento de fontes e evidências de origens diversas: documentos oficiais e militares e testemunhos de vítimas e familiares de desaparecidos políticos prestados à Comision de Verdad y Justicia do Paraguai. O argumento central dessa pesquisa consiste na afirmação de que os Arquivos do Terror, ao conterem registros sistemáticos das detenções políticas realizadas no Paraguai e no Cone Sul, contribuíram, de forma significativa, para o resgate da memória histórica do período ditatorial paraguaio. A análise dessa documentação nos permitiu, a partir do ponto de vista histórico, reconstituir a memória de um passado recente cujas lembranças e testemunhos eram constantemente questionadas judicialmente.

Palavras-chaves: Stronismo. Direitos Humanos. Arquivos do Terror. Memória. História.

\section{INTRODUÇÃO}

A descoberta dos chamados Arquivos do Terror no Paraguai em 1992 representou o desvendamento de quase meio século da história paraguaia extraoficial. O acervo de cerca de 60.000 registros revela fatos e acontecimentos que datam de 1927 a fevereiro de 1989. Estes documentos constituem registros comprobatórios

\footnotetext{
${ }^{1}$ Margarita Casco de Cano, Costa Rosado, 1980 apud COMISIÓN DE VERDAD Y JUSTICIA. Informe Final: anive haguã oiko. Assunción: Comissión de Verdad y Justicia, 2008. Tomo V.p. 247.

2 Pós-doutora em História pela Universidade Federal de Minas Gerais na área Memória e História, com ênfase no período das ditaduras militares dos países do Cone Sul na América Latina e do Brasil. Professora Adjunta do Curso de Direito do Centro Universitário UNA, onde leciona as disciplinas: História do Direito e Metodologia do Trabalho Científico. Pesquisadora do Projeto República: núcleo de pesquisa, documentação e memória, da Faculdade de Filosofia e Ciências Humanas da Universidade Federal de Minas Gerais. E-mail: annaflav@prof.una.br
} vol.09, n. 01, Rio de Janeiro, 2016.pp. 140-163 
de casos de violações de direitos humanos que tramitavam em juízo nos tribunais paraguaios, tais como tortura, desaparecimento de pessoas e troca de prisioneiros sem ordem judicial com países estrangeiros, sobretudo nos 35 anos da ditadura de Alfredo Stroessner. Além dessas provas, o acervo possui inúmeras evidências das ações e operações da Operação Condor ${ }^{3}$, que tinha como principal objetivo o intercâmbio de detidos políticos e de informações entre os países do Cone Sul.

Neste sentido, os Arquivos do Terror se constituem como um instrumento que tem possibilitado às comunidades nacional e internacional a encontrar provas e evidências contra o Estado de exceção que se instalou no Paraguai durante os anos de 1954 a 1989, bem como informações e vestígios sobre pessoas desaparecidas neste período (ANGUITA, 2001). O personalismo de Stroessner e sua certeza no apoio irrestrito dos setores sociais ao seu governo, fruto principalmente da troca de favores políticos, fez com que o ditador fosse minucioso nos registros de casos de detenção e prisão de ativistas e oposicionistas do regime militar. Diferente da maioria dos governos ditatoriais do Cone Sul, que tentou nos seus últimos dias no poder, destruir as evidências dos casos de violações de direitos humanos, a polícia da ditadura de Stroessner procurou, com a presunção de que poderia voltar a ser útil um dia, guardar toda a documentação deste período. Este fato tornou possível, após a descoberta dos Arquivos do Terror, a obtenção de valiosas informações que levavam à localização de restos mortais de centenas de desaparecidos políticos.

Os documentos encontrados revelam um quadro de intenso controle, monitoramento e vigilância sobre todos os aspectos das atividades dos opositores do stronismo (reuniões, manifestações, painéis, publicações, assembleias, listas de entidades e outras). Assim como as atividades dos ativistas políticos e opositores ao regime eram vigiadas e documentadas, a polícia política de Stroessner procurou registrar, de forma exaustiva, as atividades e ações repressivas realizadas. Com a descoberta dos Arquivos do Terror, alguns antigos colaboradores do regime optaram por fornecer informações às equipes de investigações e aos técnicos da Comision de Verdad y Justicia do Paraguai, em troca da não revelação de seus nomes. Este fato permitiu a localização de cemitérios clandestinos que levaram a descoberta de ossadas de prisioneiros políticos executados durante a ditadura de Stroessner.

Os Arquivos do Terror representam uma fonte inesgotável de testemunhos, experiências e informações sobre crimes contra os direitos humanos ${ }^{4}$, muitos deles imprescritíveis. $\mathrm{O}$ estudo de seu acervo tem contribuído

\footnotetext{
${ }^{3}$ A Operação Condor foi uma ação conjunta das forças repressoras dos países Brasil, Argentina, Chile, Bolívia, Paraguai, Uruguai, criada em 1975. A função principal dessa operação era neutralizar e reprimir os grupos que se opunham aos regimes militares montados na América do Sul. O nome da operação faz referência a uma ave andina, símbolo de astúcia na caça às suas presas, que possui parentesco com o urubu e se alimenta de animais mortos.

${ }^{4}$ Segundo Sarlet (2009), os direitos humanos são aqueles reconhecidos e firmados pelas posições jurídicas internacionais que se reconhecem ao ser humano, independentemente de sua vinculação com determinada ordem Constitucional. Os direitos humanos exprimem certa consciência universal e por isso estão acima do ordenamento jurídico de cada estado. Segundo Hunt (2009, p. 18), "Os direitos humanos requerem três qualidades encadeadas: devem ser naturais (inerentes nos seres humanos), iguais (os mesmos para todo mundo) e universais (aplicáveis por toda parte). Para que os direitos sejam direitos humanos, todos os humanos em todas as regiões do mundo devem possuí-los igualmente e apenas por causa de seu status como seres humanos".
} vol.09, nº. 01, Rio de Janeiro, 2016.pp. 140-163 
para várias pesquisas de estudiosos em todas as partes do mundo, sobretudo no que refere as violações dos direitos humanos durante o stronismo. O objetivo desse artigo é recontar parte dessa história, a história da violência do regime stronista sobre mães e crianças torturadas e presas durante a ditadura de Strossner, através dos testemunhos colhidos pela Comisión de Verdad y Justicia e das provas e evidências encontradas nos documentos dos Arquivos do Terror, localizado no Centro de Documentación y Archivo para la Defensa de los Derechos Humanos (CDyA) da Corte Suprema de Justiça do Paraguai.

Após várias tentativas de organização do acervo, os diretores do Centro de Documentación y Archivo optaram por organizá-lo utilizando as diretrizes de seus próprios proprietários: os militares. Segundo pesquisadores este sistema de organização se revelou extremamente eficaz (PAZ; AGUILAR; SALERNO, 2008). A partir do nome de um suspeito, é possível localizar, em poucos minutos, sua ficha anterior, sua foto, suas declarações durante o interrogatório, o resumo das conclusões feitas pela polícia paraguaia a respeito dos motivos da detenção daquele suspeito. Assim, seguindo esta lógica investigativa, nossa pesquisa procurou, através dos testemunhos coletados pela Comision de Verdad y Justicia, de vítimas declaradas da ditadura militar instalada por Sroessner, buscar informações, provas documentais e registros dessas pessoas no acervo dos Arquivos do Terror. A partir desses registros, cruzamos as informações com os relatos das vítimas e com a bibliografia sobre o assunto. Essa metodologia nos permitiu recontar os casos de violações dos direitos humanos que envolviam mulheres, sobretudo grávidas, e crianças, abortadas, mortas, sequestradas ou torturadas durante a última ditadura militar do Paraguai.

\section{STRONISMO: CONTEXTO HISTÓRICO}

Como todos os países da América do Sul, o Paraguai viveu décadas de ditadura militar, sob a liderança do general Alfredo Stroessner. No dia 4 de maio de 1954, Stroessner, apoiado pelo Partido Colorado e pela maioria da população, foi protagonista de um golpe de Estado no Paraguai que durou 35 anos, culminando com a perda do apoio à Stroessner dentro do próprio partido Colorado em 1989. Apesar de a ditadura paraguaia possuir semelhanças com as demais ditaduras da América do Sul, o Paraguai possui algumas peculiaridades que nos auxiliam na compreensão de sua história e, sobretudo, no apoio da sociedade civil ao Estado de exceção instaurado por Stroessner (AMARAL, 2005; PAZ, 2008).

Uma primeira característica é o fato do Paraguai ter vivido, desde a conquista da sua independência da Espanha, em uma ditadura perpétua, baseada no personalismo político e no domínio de um único partido: o Colorado. Durante toda a sua história, a única exceção foi o governo de Fernando Lugo, eleito presidente do Paraguai no dia 20 de abril de 2008, pelo Partido Liberal por $41 \%$ do total dos votos, rompendo com a hegemonia de Partido Colorado. No dia 22 de junho de 2012, Lugo foi destituído do poder pelo Senado paraguaio, através de 
um processo de impeachment, por 39 votos contra 4. Na mesma noite, o vice-presidente Frederico Franco, assumiu a presidência do Paraguai. Apesar do impeachment de Lugo ter sido considerado legítimo pelo Tribunal Superior Eleitoral do país, este fato resultou no isolamento político do Paraguai com a maioria dos países da América Latina, que se recusaram a aceitar a forma como ocorreu a destituição do ex-presidente.

Desde 1887, a alternância dos dois partidos tradicionais (colorado e liberal) nunca se resolveu pacificamente nas urnas, mas por meio de 'revoluções' - mudanças de governo por golpes de Estado, rebeliões intestinas e guerras civis - além de duas guerras internacionais - Tríplice Aliança (1865-1870) e do Chaco (19321935) - que dizimaram sua população (ALVAREZ, 2010, p. 396).

Entre 1947 a 1954, o Paraguai teve sete presidentes, todos do Partido Colorado, que firmaram uma relação direta entre o partido, o governo e as forças armadas. Entre 1954 a 1960, Stroessner se consolidou na presidência através de sucessivos expurgos de dirigentes que poderiam substitui-lo. A ditadura implantada por Stroessner durou até 1989, quando em 3 de fevereiro, um golpe de Estado encabeçado pelo general Andrés Rodríguez, um dos homens fortes do regime, que se enriqueceu com o apoio de Stroessner, destituiu o ditador e iniciou um período de abertura política no Paraguai (PAZ, 2008).

Durante seu governo, Stroessner consolidou sua liderança a partir da aliança governo, partido Colorado e forças armadas. Sua primeira ação, após se consolidar no poder, foi a reorganização do Exército, vinculando a lealdade dos comandantes militares a uma adesão pessoal ao caudilho do presidente e eliminando toda a oficialidade resistente. Nos primeiros anos de seu governo, o ditador exilou, demitiu e prendeu seus principais opositores. Proibiu atividades políticas e sociais e acabou com a liberdade de expressão e de imprensa. A propaganda política foi utilizada como principal meio de difusão do culto ao presidente e a imprensa era o meio utilizado para este fim. Durante a ditadura de Stroessner, os jornais só divulgavam informações sobre as atividades oficiais do presidente, esporte e beleza feminina, procurando transparecer, para à comunidade internacional, a existência de um clima democrático e ordeiro no Paraguai (LÓPEZ, 2010, VERA, 2010).

O êxito da estratégia de Stroessner se deve a combinação de apoios institucionais com o personalismo ${ }^{5}$ da sociedade paraguaia. Considerando a história política do país e a adesão da sociedade aos heróis militares como promotores da ordem e do progresso, o Paraguai se tornou um campo fecundo para a instalação de ditaduras autoritárias e repressivas (VERA, 2010).

Outro aspecto peculiar do stronismo é fato de não podermos considerar a ditadura imposta por Stroessner como uma ruptura do processo democrático, como ocorreu no Brasil e no Chile. Ao contrário, a ditadura de Stroessner sucedeu a uma série de períodos ditatoriais, sob a liderança de um único partido - o partido Colorado. Esta ausência de experiência cívica e democrática explica a adesão de boa parte da sociedade ao

\footnotetext{
${ }^{5}$ Segundo Alvarez (2010, p. 397) o personalismo seria "a inclinação a aderir com lealdade a um líder político em particular". vol.09, nº. 01, Rio de Janeiro, 2016.pp. 140-163
} 
stronismo, como também muitas das dificuldades da sociedade civil na promoção da fraca democracia que se instalou no Paraguai após a saída de Stroessner (LÓPEZ, 2010).

No Brasil, o regime militar implantado em 31 de março de 1964, a partir do golpe que depôs o presidente João Goulart, destituiu o estado de direito democrático através da emissão de diversos atos institucionais que ampliaram o poder executivo e reduziram os direitos individuais dos cidadãos. A partir de abril de 1964, foi instalada uma censura prévia à imprensa, aos sindicatos, às organizações estudantis e de direitos humanos sob o controle do Estado autoritário. Na conjuntura que ocorreu o Golpe de 1964, o país passava por uma crise econômica e de intensas mobilizações operárias, estudantis e camponesas. Estas mobilizações se deram em torno de reformas políticas e institucionais de caráter nacionalista, defendidas pelo presidente João Goulart e por segmentos da sociedade civil, denominadas de "reformas de base". A justificativa dos militares para a realização do golpe foi a defesa da ordem e das instituições, contra a ameaça comunista. Associados aos interesses militares, dos grandes latifundiários e dos setores da classe média, estavam os interesses da grande burguesia nacional e internacional e do governo norte-americano.

No Chile, após o golpe de estado de 1973, que culminou com a morte do governo constitucional eleito Salvador Allende no palácio presidencial, foi decretado estado de sítio e centenas de pessoas foram executadas sem julgamento prévio. Logo após o golpe, foi formada uma junta militar composta por Augusto Pinochet, comandante do Exército, Gustavo Leigh, comandante das Força Aérea, César Mendoza, general diretor dos Carabineros $^{6}$ e José Tombio Merino, almirante da Armada. Essa junta assumiu o controle da nação com o apoio da direita chilena, contrária as reformas implantadas por Allende, prometendo "restaurar la chilenidad, la justicia y la institucionalidade quebrantadas ${ }^{7 ”}$. Segundo Anthony Pereira (2010, p. 155), essa quebra da legalidade durante o regime militar chileno se deve ao fim do consenso existente sobre o estado de direito em um amplo seguimento da direita e da centro-direita, através do rompimento nas relações entre o Executivo e o Judiciário. A polarização política que marcou o governo de Salvador Allende, levando a criação de grupos armados tanto na direita como na esquerda, se agravou após a sua queda. As leis de Segurança Estatal (1958) e de Controle de Armas (1973) oficializaram o controle do Executivo pelos militares e estes, após conquistar efetivamente o Executivo, promoveram um rompimento entre os tribunais civis e militares. Esta situação tornou possível a junta militar uma atitude ofensiva diante das resistências ao regime e uma intensificação da repressão no Chile, rompendo com a histórica legalidade chilena.

Outra peculiaridade da ditadura de Stroessner foi o período e o tempo da sua duração. A golpe militar responsável pela instalação da ditadura paraguaia se deu em 1954, muitos anos antes das demais ditaduras

\footnotetext{
${ }^{6}$ Os Carabineros são as forças de segurança do Chile, desde sua criação em 1927. É uma polícia uniformizada que atuam em caráter preventivo para garantir a manutenção da ordem e segurança do país.

${ }^{7}$ Acta de Constitución de la Junta de Gobierno, Decreto-Lei no 1 , de 11 de setembro de 1973.
} vol.09, nº. 01, Rio de Janeiro, 2016.pp. 140-163 
instaladas na América do Sul. O próximo país a sofrer um golpe militar e instalar uma ditadura foi o Brasil em 1964. O fim da ditadura paraguaia se deu em 1989, com um golpe militar, coordenado pelo próprio Partido do ditador Stroessner. Trata-se, portanto, de uma ditadura de longa duração - trinta e cinco anos de governo unipessoal e abrangente, baseado na lealdade, na troca de favores e no clientelismo nas relações sociais e políticas (PAZ, 2008; LÓPEZ, 2010).

Stroessner procurou se cercar de pessoas leais dentro das forças armadas. Essa lealdade era mantida através de uma política de benefícios especiais e favores, o que contribuiu para o enriquecimento rápido de muitos de seus aliados, entre eles Andrés Rodríguez, responsável pelo golpe militar que destitui Stroessner do poder em 1989. O mesmo tipo de política de privilégios e benefícios ocorreu no Partido Colorado. A filiação ao partido era condição crucial para ser funcionário público, ser promovido ou nomeado. Em todo país, as pessoas procuravam os organismos de base do Partido Colorado para solicitar favor, emprego ou privilégios. A obtenção desses favores estava vinculada ao fato do cidadão trabalhar para o partido e para o Estado, numa relação que mesclava consentimento, medo e subserviência. Aqueles que não se filiavam ao partido não tinham a mesma sorte nas conquistas profissionais e acadêmicas que os filiados ao Partido Colorado tinham, além de serem alvos de vigilância e desconfiança, quando não de intolerância e repressão (ARDITI, 1992; VERA, 2010).

Stroessner desenvolveu uma cultura do medo, da obediência, mas também do culto a sua personalidade e a sua pessoa. A adulação e submissão à Stroessner se converteram em instrumentos de mobilidade social e de acesso aos cargos públicos (LÓPEZ, 2010). No período em que Stroessner esteve no poder, seu governo adotou a ditadura como forma de governo. Seu caráter autoritário era baseado em uma atitude anticomunista, o que justificava as frequentes violações dos direitos humanos daqueles cidadãos tidos como comunistas, subversivos ou inimigos internos. Dentro da ideologia da Doutrina da Segurança Nacional ${ }^{8}$, a adoção do anticomunismo como política de Estado era fundamental para a eliminação do inimigo interno e a restituição do estado de paz e ordem social, eliminando a ameaça de uma revolução socialista, como a ocorrida em Cuba, em 1954.

Para alimentar este culto de sua personalidade, Stroessner fez uso intenso da propaganda política e cívica do governo. A pacificação social, a estabilidade econômica e a contenção do comunismo eram os pilares da propaganda stronista que recebia apoio de vários setores da sociedade. A fim de realizar esses objetivos o Estado ditatorial contou com a estrutura repressiva da polícia política da capital do país e com uma complexa rede de

\footnotetext{
${ }^{8}$ Esta doutrina, originada na Escola Superior de Guerra dos Estados Unidos da América, foi amplamente adotada pelas forças armadas dos países latino-americanos para combater os inimigos do Estado. A base dessa doutrina era as concepções positivistas que buscavam interpretar o corpo político e social a partir de um modelo orgânico, cujo funcionamento perfeito dependia do funcionamento adequado de todas as partes que compunha o restante do corpo. Assim, aquele seguimento ou grupo que não adotasse essa lógica estaria minando o funcionamento harmônico do corpo social e, portanto, deveria ser eliminado. Esta visão ideológica não admitia diversidade de pensamentos ou de ações, nem críticas, nem dissidências. Todos aqueles que se opunham a lógica positivista deveriam ser automaticamente eliminados a fim de garantir o bom funcionamento do corpo social em constante desenvolvimento.
} 
informantes e delatores que vigiavam permanentemente as atividades políticas e sociais da população (PAZ, 2008; LÓPEZ, 2010; VERA, 2010).

Durante a ditadura de Stroessner, milhares de paraguaios foram presos e torturados por razões políticas. Houveram exílios em massa de refugiados paraguaios para a Argentina, último país do Cone Sul a sofrer um golpe militar. Entre os principais impactos da repressão promovida pela ditadura paraguaia (1954-1989) destacam-se: restrição da liberdade de comunicação, controle total da vida cotidiana da população, isolamento social das vítimas da repressão, desorganização das organizações opositoras e ataque às lideranças, impotência e conformidade da sociedade civil diante do autoritarismo e da propaganda ufanista do governo (COMISION, t. V, 2008; PAZ, 2008; VERA, 2010, LÓPEZ, 2010).

Estes impactos possuem uma dimensão acumulativa no tempo, nas vítimas e nas comunidades e organizações afetadas. Numerosas vítimas da ditadura foram perseguidas e sofreram violações em diferentes momentos, tais como torturas, detenção arbitrária e exilio. Além disso, aqueles que sobreviveram à repressão durante a ditadura posteriormente foram perseguidos e estigmatizados. As principais violações dos direitos humanos cometidas foram: detenções arbitrárias e tortura, incluindo violência sexual, desaparecimentos forçados e execuções extrajudiciais de opositores políticos ou membros de organizações armadas, exílio e banimento, ataques às comunidades nas áreas rurais com um forte impacto coletivo, gerando medo e alteração nas condutas coletivas (COMISIÓN, t. V, 2008, p. 18).

Segundo informe final da Comissão da Verdade e Justiça do Paraguai, no dia 15 de março de 1982, a polícia de Assunção anunciou à imprensa nacional ter desfeito uma célula do Partido Comunista do Paraguai, cujo dirigente era Oscar Creydt, que estava exilado. Segundo a polícia, o líder do grupo era Antônio González Arce. Ele foi o único membro preso a reconhecer a sua participação no Partido Comunista Paraguaio (PCP). Os demais detidos sempre negaram nos interrogatórios envolvimento com o PCP. Todos eles foram torturados e mantidos isolados nos centros de detenção e tortura, em celas com condições desumanas de sobrevivência (COMISIÓN, t. VIII, 2008, p. 356).

Os principais métodos adotados nas torturas físicas dos prisioneiros eram golpes, descargas elétricas, submersão, sufocamentos, queimaduras, violações e agressões sexuais. Quanto à tortura psicológica os principais métodos empregados eram o isolamento, ameaças, humilhação, simulação de execuções, obrigação de presenciar a tortura de outros companheiros (COMISION, t. V, 2008).

As violações dos direitos humanos não se restringiram aos militantes, ativistas e opositores do regime de Stroessner. Elas abrangeram seus filhos e filhas, ainda crianças, que guardam até o presente as sequelas dessas violações. Do total de testemunhos coletados pela Comisión da Verdad y Justicia do Paraguai, 13\% eram de 
crianças e adolescentes que tiveram seus direitos humanos violados durante a ditadura militar do Paraguai (COMISIÓN, t. V, 2008, p. 247).

Estas violações deixaram impactos profundos nas vidas dessas crianças e adolescentes relacionados em três situações. A primeira está na própria experiência traumática passada por essas crianças que foram presas e torturadas, muitas delas sofreram inclusive violência sexual. Além disso, muitas crianças presenciaram a tortura de seus pais durante os interrogatórios. Há ainda os estigmas sofridos por essas crianças que eram tratadas pela sociedade e pelos próprios vizinhos como comunistas, sendo isoladas socialmente nas comunidades em que viviam (CONADEP, 1986; COMISION, t. V, 2008).

Outra situação é quando da perda de entes queridos, privando as crianças de um apoio afetivo fraternal, da coesão familiar e da presença dos pais no desenvolvimento pessoal e social, causando várias sequelas psicológicas. Tão traumático para os filhos de prisioneiros políticos quanto a perda dos seus pais, era a detenção arbitrária dos mesmos e o período de separação que vivenciavam enquanto seus pais estavam presos.

O retorno de prisioneiros políticos após longos períodos de detenção e tortura dificultava o regresso dos sobreviventes ao núcleo familiar. As sequelas dessas violações ultrapassaram os limites dos centros clandestinos de detenção e invadiram o espaço privado do torturado, moldando suas ações e relações sociais e familiares. A sensação de vigilância constante converteu antigos amigos em potenciais alvos ou delatores. As relações de amizade passavam pelo cunho da censura, do medo e da desconfiança. $O$ testemunho a seguir ilustra o sentimento de uma criança ao ver seus pais sendo torturados.

Yo supuestamente me iba para traer la comida, me fui a verle a mi papá, inclusive le toqué, estaba todo duro ya, y vine y le conté a mi hermano que papá ya murió, y a mamá ya le vi en una esquina, toda ensangrentada, estaba mal luego ya”. (Emigdio Fleitas Arias, Caaguazú, 1980 apud COMISIÓN, TOMO V, 2008, p. 248).

Uma terceira situação é o fato das crianças terem que deixar a cidade, a escola e os amigos em função dos perigos e ameaças que seus familiares passavam. A criação de laços afetivos duradouros não era possível para essas crianças. As relações sociais eram efêmeras e superficiais, pois qualquer aproximação mais íntima representava uma ameaça à integridade física, psicológica e social dos envolvidos.

Segundo dados da Comisión de Verdad y Justicia, das 639 crianças, filhas das vítimas da ditadura de Stroessner, 67\% declararam ter sofrido sequelas desse período (COMISIÓN, t. V, 2008, p, 251). O quadro abaixo faz um levantamento das sequelas apresentadas por essas crianças.

Quadro 1: Sequelas sofridas pelos filhos das vítimas da ditadura paraguaia (1954-1989)

\begin{tabular}{|c|c|c|}
\hline Sequelas nos filhos & Valor absoluto & $\%$ \\
\hline Medo & 113 & $21,7 \%$ \\
\hline Depressão & 108 & $20,7 \%$ \\
\hline Pobreza & 97 & $18,6 \%$ \\
\hline Dificuldade para estudar & 91 & $17,5 \%$ \\
\hline
\end{tabular}




\begin{tabular}{|c|c|c|}
\hline Estigmatização & 63 & $12,1 \%$ \\
\hline Migração & 63 & $12,1 \%$ \\
\hline Transtorno do sono & 57 & $10,9 \%$ \\
\hline Crises de angústia & 52 & $10 \%$ \\
\hline Dificuldade para trabalhar & 49 & $9,4 \%$ \\
\hline Problemas de comportamento & 26 & $5 \%$ \\
\hline Ressentimento com os pais & 24 & $4,6 \%$ \\
\hline
\end{tabular}

Fonte: COMISIÓN DE VERDAD Y JUSTICIA. Informe Final: anive haguã oiko. Assunción: Comissión de Verdad y Justicia, 2008. Tomo V.p. 252.

Vale ressaltar que a situação dos filhos e filhas dos opositores políticos era determinada pela situação em que se encontravam suas mães. Haviam mulheres que eram detidas junto com seus filhos, mulheres que estavam grávidas e tiveram seus filhos durante o período de sua detenção e mulheres que tiveram que deixar seus filhos com outras pessoas devido a sua captura e detenção. Na maior parte dos testemunhos coletados pela Comisión de Verdad y Justicia do Paraguai, o período de detenção durava em torno de 2 ou 3 anos (COMISIÓN, t. V, 2008).

Estas violações dos direitos humanos aconteceram no Paraguai diante da indiferença da comunidade internacional, mais atenta as notórias violações nos países vizinhos (Brasil, Chile, Argentina, Uruguai). Na metade da década de 1980, a ditadura paraguaia começou a perder sua base de legitimidade social. A recessão econômica do período gerou contínuo descontentamento dos setores que sustentavam o regime em troca de favores e privilégios (LÓPEZ, 2010, p. 463). Ao mesmo tempo, os países vizinhos que passaram por experiências ditatoriais estavam retornando aos estados de direito democrático, devido, em parte, à pressão internacional pelo respeito aos direitos humanos. Neste contexto, Stroessner e sua ditadura perdiam cada vez mais apoio.

Com a diminuição do volume de recursos para manter os favores e privilégios, houve a redução da legitimidade do ditador e de seu governo. Além disso, uma divisão no próprio partido Colorado enfraqueceu ainda mais a cumplicidade social do partido com o ditador. Todavia, manteve-se no Paraguai a corrupção partidária, a política de benefícios econômicos e a impunidade em troca da adesão e lealdade ao partido. Stroessner caiu devido a sua incapacidade de gestão ao conduzir o país para uma recessão econômica que cerceou seus apoios políticos e minou sua credibilidade enquanto líder, mas o aparelho de estado manteve intacto a sua estrutura montada no período da ditadura.

Em 1992, com a descoberta dos Arquivos do Terror, a memória da repressão viveu um novo capítulo em sua história, marcada por omissões, violências, torturas, consensos e consentimentos. A memória destes anos deve ser reconstruída incluindo o sofrimento das vítimas pelas vidas que foram despedaçadas, pelas infâncias dilaceradas, pelas gerações silenciadas. 


\section{ARQUIVOS DO TERROR E SUA IMPORTÂNCIA}

A ditadura paraguaia (1954-1989) gerou traumas e ressentimentos ainda presentes na população. Como todas as ditaduras latino-americanas, ela violou os direitos humanos, cerceou liberdades e promoveu mortes e desaparecimentos de cidadãos em nome da Segurança Nacional. Uma das vítimas da ditadura paraguaia durante o governo do general Stroessner foi o advogado Martín Almada que, desejoso de conhecer detalhes das acusações que o colocara preso entre 1974 a 1977 e da morte de sua esposa, solicitou um habeas data às autoridades judiciais paraguaias.

Em 1992, atendendo ao pedido de habeas data ${ }^{9}$ do advogado, as autoridades encontraram em Lambaré, cidade que fica a vinte quilômetros de Assunção, um acervo composto de cerca de 60.000 registros de documentos contendo informações sobre a ditadura do general Stroessner. Através da exigência do cumprimento de seu direito de habeas data, Martín Almada contribuiu para desmantelar um gigantesco volume documental que tornou possível recontar a história do stronismo. Entre os documentos encontrados ressaltam-se os documentos relativos ao funcionamento da Operação Condor com a ação conjunta dos países Brasil, Paraguai, Chile, Uruguai, Argentina. Segundo López (2010), antes de assumir a presidência Stroessner se reuniu secretamente com membros do Comando Sul dos Estados Unidos. Nesta reunião foi assinado um pacto envolvendo altos oficiais americanos e brasileiros, como parte do plano dos aliados anticomunistas durante a Guerra Fria e a Doutrina de Segurança Nacional, implantada na década de 1960, por meio da ditadura militar brasileira (PAZ, 2008; LÓPEZ, 2010, p. 470).

A base de dados dos Arquivos do Terror está localizada no Centro de Documentação e Arquivo para a Defesa dos Direitos Humanos (CDyA) do Supremo Tribunal de Justiça do Paraguai. Esta base de Base de dados foi desenvolvida através do Projeto Memória Histórica, Democracia e Direitos Humanos (MHDDH), acordo firmado entre o Supremo Tribunal de Justiça, da Universidade Católica de Assunção e da ONG The National Security Archive. Cada registro inclui o código para imagens de microfilme, data do documento, tipo de documento, linha e nome; e se for o caso, a origem, as organizações e localização geográfica. São fichas policiais, listas de entradas e saídas de presos, notas dos chefes de investigações, informes confidenciais, controle de partidos políticos, publicações periódicas, listas de suspeitos, informações sobre agremiações e grupos considerados subversivos, controle de sindicatos e objetos como livros e cédulas de identidade.

\footnotetext{
${ }^{9}$ Habeas data "é uma ação garantida constitucionalmente que assegura a qualquer cidadão o livre acesso às informações existentes em registros ou bancos de dados governamentais ou de caráter público relativas à sua pessoa, a fim de protegê-lo, por exemplo, contra o uso abusivo destas informações adquiridas de forma fraudulenta e ilícita. Além disso, é uma garantia constitucional dos direitos à intimidade, à privacidade, à honra e à imagem, que permite o acesso e a retificação à informações referente ao impetrante". Fonte: http://www.direitonet.com.br/dicionario/exibir/174/Habeas-data.
} 
Os documentos encontrados e identificados dão uma ideia do amplo sistema de informação e vigilância, bem como das organizações e setores que eram vigiados pelos agentes da repressão. Nos Arquivos do Terror podemos encontrar registros de entrada e saída dos presos, anotações aos chefes das investigações, informes confidenciais, informes de vigilância domiciliar dos opositores do regime, disposições administrativas, declarações indagatórias dos prisioneiros, lista de presos detidos nos quarteis, controle dos partidos políticos, controle dos centros estudantis, publicações periódicas, informes sobre grupos subversivos e controle de sindicatos.

Esses registros auxiliaram advogados de presos políticos a encontrar evidências judiciais de suas prisões e das circunstâncias de sua detenção. Esses documentos serviram para desmentir as falsas alegações do Estado que, até a descoberta dos Arquivos do Terror e a organização de seus registros, negavam sistematicamente a detenção de vários cidadãos paraguaios e de outras nacionalidades, muitos deles desaparecidos políticos. Assim, um valor irrefutável destes arquivos é o suporte jurídico que seus documentos possibilitaram nos processos judiciais movidos contra o Estado após o término da ditadura de Stroessner. Além disso, devido a riqueza dos detalhes e dos registros, à amplitude e diversidade dos documentos, esses documentos encontrados nos Arquivos do Terror serviram como suporte documental a inúmeros julgamentos realizados contra os agentes repressores argentinos e chilenos, devido a participação destes no contexto da Operação Condor (PAZ, GONZÁLEZ, AGUILAR, 1994; DINGES, 2005; ALMADA, 2013).

Para centenas de paraguaios vítimas da repressão stronista, estes arquivos representaram evidências inquestionáveis de suas detenções e dos danos sofridos pelas mesmas. A partir desses documentos abriu-se a possibilidade de aplicação do direito de habeas data, que passou a assumir uma utilidade concreta nos julgamentos de reparação e indenização destas pessoas. A descoberta dos Arquivos do Terror possibilitou não apenas o encontro de evidências da detenção do advogado Martín Almada como também de centenas de detenções arbitrárias de cidadãos de diferentes nacionalidades no Paraguai.

A Comissão da Verdade e Justiça do Paraguai, desde a sua criação em 2003, tem recorrido aos documentos dos Arquivos do Terror como evidências comprobatórias das detenções das pessoas que testemunharam para a Comissão, contrastando o conteúdo dos testemunhos com os registros dos documentos encontrados.

Outro valor inquestionável dos Arquivos do Terror é a sua relevância histórica. A pesquisa, leitura e análise dos documentos tornaram possível aos estudiosos, de diversas áreas e nacionalidades, reconstituir a história dos trinta e cinco anos do stronismo. A partir da análise desses documentos foi possível à comunidade acadêmica e jornalística, aos familiares das vítimas e às organizações de direitos humanos conhecer detalhes de uma história omitida pelo Estado paraguaio, sistematicamente negada nos tribunais nacionais e internacionais e violentamente silenciada pelos agentes da repressão. Com a descoberta de novas evidências sobre o stronismo, 
temas como relações de poder predominantes durante o governo de Stroessner, a sujeição do Estado paraguaio à Doutrina de Segurança Nacional, o nível de conhecimento e influência dos Estados Unidos da América na Operação Condor, os diferentes graus de resistências das organizações opositoras, o nível de conivência do partido Colorado com as violações dos direitos humanos, o amplo controle que a população paraguaia sofria sobre as suas atividades políticas e sociais puderam ser retrabalhados sob uma nova análise metodológica e documental.

Há de destacar ainda a relevância política da descoberta dos Arquivos do Terror. Após a descoberta desses arquivos a percepção da sociedade paraguaia sobre o stronismo mudou radicalmente, tanto das gerações que viveram durante o período autoritário como das novas gerações (PAZ, 2008). Após 1992, já não era mais possível negar as centenas de violações dos direitos humanos realizadas durante o governo de Stroessner e nem mesmo a sua cumplicidade com essas ações arbitrárias e desumanas. A descoberta dos Arquivos do Terror no Paraguai e sua abertura para pesquisa pública levou ao conhecimento das gerações atuais e futuras a realidade da política de eliminação do inimigo interno, dos comunistas e dos subversivos aplicada durante a ditadura de Stroessner. O horror vivenciado nos centros clandestinos de detenção e a eliminação sumária dos opositores abriu um vácuo de intolerância e medo na sociedade paraguaia, ainda incapaz de lidar plenamente com a memória desses fatos, mas capaz de desejar que fatos como estes não voltem a acontecer no Paraguai (JELIN, 2002; PAZ, 2008).

A apropriação ilegal de crianças, filhas das ditaduras e vítimas do terrorismo de estado que maculou as sociedades no Cone Sul e no Brasil, não pode mais ser esquecida. Na Argentina e no Uruguai as usurpações dos direitos humanos de crianças e adolescentes por motivos políticos, seres inocentes dessa guerra suja promovida contra o inimigo interno, não encontram mais respaldo social. Nos tribunais que julgam os casos de violações dos direitos humanos durante o período ditatorial prevalecem o testemunho dos sobreviventes dos centros clandestinos de detenção e dos familiares dos desaparecidos políticos.

Na Argentina, após a restauração do governo constitucional foram realizadas investigações a respeito da prática sistemática adotada pelo estado ditatorial de apropriação de filhos de pais supostamente "subversivos" nascidos em cativeiro. Os pesquisadores tiveram conhecimento da existência de um plano deliberado para aplicação de ordens secretas anti-subversivas, emitidas pelo Chefe do Estado Maior, o general Jorge Rafael Videla, em 17 de dezembro de 1976, que determinava como os agentes deveriam agir nas operações de segurança, durante a detenção de homens, mulheres e crianças. Segundo os investigadores existia um documento específico intitulado "Instrucciones sobre el procedimiento a seguir con menores de edad hijos de dirigentes políticos o gremiales cuando sus progenitores se encuentran detenidos o desaparecidos", proveniente do Ministério do Interior, de abril de 1977. Contudo, acredita-se que este documento tenha sido destruído após o término do 
regime militar $\operatorname{argentino~}^{10}$. A presunção da existência desse documento baseia-se nas semelhanças dos testemunhos dados pelos familiares, pelos vizinhos de desaparecidos políticos argentinos e pelos sobreviventes dos centros clandestinos de detenção dados à Comissão Nacional sobre o Desaparecimento de Pessoas (CONADEP, 1986).

A análise do acervo dos Arquivos do Terror tornou possível o conhecimento da metodologia adotada pelos agentes da repressão durante as operações de sequestro, desaparecimentos e apropriações ilegais de crianças, filhas de supostos "subversivos" políticos. A partir desses e de outros documentos (denúncias dos refugiados políticos, sobretudo uruguaios e argentinos, de correspondências, folhetos das Abuelas de Praza de Mayo $^{11}$, solicitações de habeas corpus, fichas de prisioneiros políticos e torturados, recortes de jornais e dossiês de crianças desaparecidas) encontrados em diversos arquivos oficiais que buscam registrar a memória desses fatos nos países do Cone Sul, busca-se recontar a história do processo de desaparecimento, apropriação e localização de crianças sequestradas pelos agentes das forças de segurança. Algumas dessas crianças foram sequestradas juntos com seus pais, outras nasceram em cativeiro junto com suas mães detidas grávidas. Há casos de crianças sequestradas ou apropriadas de forma ilegal que desconhecem sua verdadeira origem biológica, histórica e social. Tratam-se de crianças cujos familiares não comunicaram seu desaparecimento por medo ou ignorância dos fatos. Muitas crianças nascidas em cativeiro e adotadas ilegalmente permanecem sem conhecer a sua identidade biológica. Segundo a Associação das Abuelas de Plaza de Mayo, estima-se que cerca de 500 crianças foram raptadas, "já que muitos casos não foram denunciados ${ }^{12 "}$.

Sobre essas crianças, vítimas inocentes e incapazes de se defenderem contra o terrorismo de Estado vigente na América do Sul, durante a segunda metade do século XX, se abateu diversas violências. Elas foram brutalmente separadas de seus pais vítimas de sequestros, raptos e adoções ilegais. Tiveram sua identidade ocultada ou falsificada, sendo-lhes negado o conhecimento de sua própria história, de seus nomes verdadeiros, das datas de seus nascimentos e da identidade de seus pais biológicos. A falsificação de certidões de nascimento contou com a cumplicidade de médicos e servidores públicos que contribuíram para a intensificação dessa violência, para a anulação dos laços fraternais, para a ocultação da verdade dos fatos.

Do ponto de vista histórico, a reconstituição das memórias via análise dessas fontes arquivistas possibilitou o conhecimento de fatos que mancharam a história dos direitos humanos no Cone Sul e no Brasil,

\footnotetext{
10 Camara de Diputados de la Provincia de Buenos Aires. Disponível em: http://www.google.com.br/url?sa=t\&rct=j\&q=\&esrc=s\&source=web\&cd=1\&ved=0CB4QFjAA\&url=http\%3A\%2F\%2Fwww.hc diputados-ba.gov.ar\%2Fproyectos\%2F10-11D5770.doc\&ei=ICXvVMz-

N8_9gwTb_YC4Dg\&usg=AFQjCNFWhNtZEMGVxoCXDo5ouI5-Q0mfBg. Acesso em: 13 fev. 2014.

11 Organização de direitos humanos argentina, fundada em 1977, que tem como finalidade localizar e restituir às suas famílias legítimas todos os filhos sequestrados e desaparecidos durante a última ditadura militar argentina (1976-1983). Essas avós ficaram conhecidas no mundo inteiro como símbolo da luta contra a ditadura em defesa dos direitos humanos e do direito de voltar a ter o convívio com seus netos e netas.

${ }^{12}$ Abuelas de Plaza de Mayo. Disponível em: http://www.abuelas.org.ar/portugues/psicologica.htm. Acesso em: 15 fev. 2014.
} vol.09, n. 01, Rio de Janeiro, 2016. pp. 140-163 
mas que necessitam serem lembrados, discutidos e atualizados para que as sociedades civis desses países possam se posicionar diante da veracidade dos fatos e, se julgar necessário, responsabilizar os culpados dos crimes contra a humanidade.

A análise dessa documentação permitiu aos pesquisadores, acadêmicos, advogados e familiares de desaparecidos e presos políticos reconstituir a memória de um passado recente cujas lembranças e testemunhos eram constantemente questionadas do ponto de vista jurídico. Vale ressaltar que a descoberta dos arquivos secretos da polícia paraguaia possibilitou a comprovação de fatos sistematicamente negados pelos governos militares, tais como a existência da "Operação Condor" e o protagonismo brasileiro na troca de informações sobre prisioneiros políticos e técnicas de interrogatório, com estreita cooperação dos países do Cone Sul durante os interrogatórios. Nesse sentido, do ponto de vista documental, os Arquivos do Terror representam um acervo indispensável para as investigações históricas e para a memória do stronismo.

Por fim, os Arquivos do Terror possuem um valor simbólico inquestionável. Dada a relevância de seus registros e dos conteúdos presentes neles, eles se constituíram em símbolo de uma época, de um tempo onde a sociedade se propõe a romper com um passado ditatorial e inaugurar uma era de democracia e de cidadania. A data de 22 de dezembro, data da descoberta dos Arquivos do Terror, foi declarada como "Dia da Dignidade Nacional" no Paraguai (PAZ, 2008, p. 27-43).

\section{ALGUNS CASOS DE VIOLAÇÕES DOS DIREITOS HUMANOS DE MULHERES E CRIANÇAS}

A ditadura de Stroessner cometeu graves violações dos direitos humanos de mulheres, crianças e adolescentes. Muitas das mulheres detidas eram mães e tiveram que se afastar dos seus filhos em função de sua captura e prisão. Outras foram violentadas e abusadas sexualmente, deixando sequelas nunca superadas em sua condição de maternidade. E outras eram torturadas na presença de filhos ou filhas, como meio utilizado pelos agentes da repressão para obter informações sobre organizações opositoras do regime e do paradeiro das lideranças dessas organizações (COMISION, t. V, 2008).

Mas há ainda aquelas mulheres, detidas e presas grávidas que foram vítimas de tortura e, em função das brutalidades das condições em que os interrogatórios eram proferidos, vieram a abortar seus filhos ou filhas, que tiveram seus direitos de nascer negados por um estado de exceção que adotou como técnicas de interrogatório a prática da tortura para obtenção de informações consideradas relevantes para a segurança nacional. Baseada na Doutrina de Segurança Nacional, o estado paraguaio adotou intensamente os métodos de interrogatórios do país vizinho (Brasil), cujos agentes da repressão acreditavam que "filhos dessa raça não devem nascer", conforme 
depoimento de Hecilda Fontelles Veiga, presa no Brasil em 1971. O testemunho que se segue subsidia essa informação.

Quando fui presa, minha barriga de cinco meses de gravidez já estava bem visível. Fui levada à delegacia da Polícia Federal, onde, diante da minha recusa em dar informações a respeito de meu marido, Paulo Fontelles, comecei a ouvir, sob socos e pontapés: 'Filho dessa raça não deve nascer'. Depois, fui levada ao Pelotão de Investigação Criminal (PIC), onde houve ameaças de tortura no pau de arara e choques. Dias depois, soube que Paulo também estava lá. Sofremos a tortura dos 'refletores'. Eles nos mantinham acordados a noite inteira com uma luz forte no rosto. Fomos levados para o Batalhão de Polícia do Exército do Rio de Janeiro, onde, além de me colocarem na cadeira do dragão, bateram em meu rosto, pescoço, pernas, e fui submetida à 'tortura científica', numa sala profusamente iluminada. A pessoa que interrogava fi cava num lugar mais alto, parecido com um púlpito. Da cadeira em que sentávamos saíam uns fi os, que subiam pelas pernas e eram amarrados nos seios. As sensações que aquilo provocava eram indescritíveis: calor, frio, asfixia. De lá, fui levada para o Hospital do Exército e, depois, de volta à Brasília, onde fui colocada numa cela cheia de baratas. Eu estava muito fraca e não conseguia ficar nem em pé nem sentada. Como não tinha colchão, deitei-me no chão. As baratas, de todos os tamanhos, começaram a me roer. Eu só pude tirar o sutiã e tapar a boca e os ouvidos. Aí, levaram-me ao hospital da Guarnição em Brasília, onde fiquei até o nascimento do Paulo. Nesse dia, para apressar as coisas, o médico, irritadíssimo, induziu o parto e fez o corte sem anestesia. Foi uma experiência muito difícil, mas fiquei firme e não chorei. Depois disso, fi cavam dizendo que eu era fria, sem emoção, sem sentimentos. Todos queriam ver quem era a 'fera' que estava ali.13

O caso de Maria Margarita Baez de Britez é elucidativo dessa situação. O martírio de sua detenção fez dela um símbolo da resistência ao governo de Stroessner durante a ditadura militar paraguaia. No dia 7 de junho de 1982, o advogado da Comissão de Igrejas, Bertolucci Diego, denunciou o abuso físico sofrido por Maria Margarita Baez durante sua detenção, que ficou mentalmente perturbada devidos aos efeitos da tortura brutal que havia sofrido no Departamento de Investigação de Assunção. Em dezembro de 1982 ela foi condenada a quatro anos e oito meses. Em junho de 1984, o Tribunal de Apelação absolveu Maria Margarita Baez da culpa e da pena. Contudo, ela só foi libertada em 13 de dezembro de 1985 (COMISÍON, t. VIII, 2008, p. 356-357). O depoimento de Maria Margarita Baez sobre as circunstâncias de seu interrogatório e de sua prisão é estarrecedor $^{14}$. A brutalidade das torturas sofridas é elucidativa do grau de repressão e violação dos direitos humanos promovidos pelo stronismo.

\footnotetext{
${ }^{13}$ Hecilda Fontelles Veiga, ex-militante da Ação Popular (AP), era estudante de Ciências Sociais quando foi presa, em 6 de outubro de 1971, em Brasília (DF). Fonte: MERLINO, Tatiana; OJEDA, Igor (Orgs). Direito à memória e à verdade: Luta, substantivo feminino. São Paulo: Caros Amigos, 2010.p. 76.

${ }^{14}$ Relatório de Maria Margarita Baez de Britez, disponível nos Arquivos do Terror, localizado no Centro de Documentación y Archivo para la Defensa de los Derechos Humanos (CDyA) da Corte Suprema de Justiça do Paraguai.
} vol.09, nº. 01, Rio de Janeiro, 2016.pp. 140-163 
Maria Margarita Baez foi detida no dia 17 de agosto de 1976 em uma via pública por homens vestidos de civis. Eles a renderam e a arrastaram. Diante do desconhecimento do que estava acontecendo, da identidade dos homens e temendo pela sua vida, ela gritou na esperança de que alguém a ajudasse. Os homens que realizavam a operação de sequestro, percebendo que as pessoas saíram na varanda de suas casas para ajudá-la, se identificaram como policiais investigativos e pediram reforço policial. Minutos depois ela foi cercada por vários policiais e um veículo. Ela foi levada encapuzada para o Departamento de Investigações de Assunção.

Logo que chegou, durante o seu interrogatório, ela recebeu vários golpes de cachiporra ${ }^{15}$ por todo o corpo. Posteriormente foi conduzida para uma banheira com uma água suja de sangue, cabelos, etc. Naquela ocasião, os agentes da repressão tiraram sua roupa, amarraram seus braços e pés e a colocaram sentada na banheira. Em seguida chegaram mais três policiais, cujo nome de um deles era Lucilo Benítez que a ameaçou para que contasse tudo que sabia sobre seus companheiros e onde eles viviam, caso contrário ela iria morrer. Ela então informou aos agentes que desconhecia o motivo pelo qual estava lá e que temia pela vida de seu filho, pois estava grávida de quatro meses. Os agentes a introduziram na água várias vezes com o objetivo de afogá-la. Quando eles perceberam que ela quase não conseguia respirar, bateram no seu estômago e em seus ouvidos, sempre insistindo com as mesmas perguntas. Disseram que aquilo era apenas um batismo e que se ela não contasse o que eles queriam saber, mais tarde iria implorar para que a matassem e também matassem seu filho.

No dia seguinte ela foi levada até o Pastor Coronel $^{16}$ que ordenou aos agentes que fizessem o que quisessem com ela. Depois dessa ordem, os torturadores a transportaram para uma outra sala onde foi novamente torturada. Naquela sala, os agentes chutaram-na nas pernas, colocaram cigarros acesos entre os dedos de seus pés e golpearam sua cabeça com um objeto parecido com um cinzeiro de metal. Como consequência desses golpes na cabeça, Maria Margarita Baez sofreu uma lesão (que só tomou conhecimento a partir de um exame e diagnóstico de um médico neurológico argentino Dr. Didman). Na mesma noite ela foi levada para outra sala onde os agentes a jogaram no chão e bateram em todo o seu corpo com um chicote. Disseram que eles iriam romper seus pés para que nunca mais pudesse andar. Ao ouvir isso, ela colocou suas mãos sobre seus pés e os golpes continuaram. Durante seu flagelo ela quebrou um dos dedos de sua mão e sofreu vários desmaios. Outros presos escutaram sua tortura. Era uma espécie de tortura psicológica utilizada pelos agentes da repressão para amolecer e amendrontar os presos, facilitando a delação e o fornecimento das informações solicitadas durante o interrogatório.

\footnotetext{
${ }^{15}$ Cachiporra é uma arma de mão de caráter dissuasivo e consistente. Possui uma alça flexível com um núcleo de madeira, borracha ou metal. É utilizada por alguns policiais e guardas civis no mundo. Atualmente seu uso é considerada ineficiente e questionado em termos de direitos humanos.

${ }^{16}$ Pastor Milciades Coronel foi chefe do Departamento de Investigações da Polícia de Assunção (Paraguai) durante grande parte da ditadura do general Alfredo Stroessner. É considerado uma figura emblemática da repressão e foi responsável por inúmeros casos de violações dos direitos humanos.
} 
Diante da denúncia pública de sua prisão eles foram obrigados a levá-la para tratar de seus ferimentos. Foi feita uma atadura no seu dedo fraturado e nas unhas arrancadas. Posteriormente ela foi internada por seis dias por causa do falecimento de seu filho, ainda em seu ventre. O aborto que ela sofreu foi devido aos golpes e surras que levou durante o seu interrogatório.

No dia 28 de setembro foi conduzida ao presídio de Emboscada, onde se encontravam cerca de 500 presos políticos. Em dezembro deste 1976 foi colocada em liberdade sem responder processo, ameaçada de morte e sem os documentos de identidade.

Em 16 fevereiro de 1982 foi novamente sequestrada e conduzida encapuzada ao Departamento de Investigações, desconhecendo as acusações que pesavam sobre ela. Ela foi conduzida para o Cassino dos Oficiais. Neste local ficou pendurada a uma barra de ferro, com as mãos amarradas durante seis dias, sem comida e acordada (os agentes da repressão derramavam constantemente água gelada nela). Uma vez por dia ela era desamarrada para que os agentes praticassem outras formas de tortura. Frequentemente eles queimavam suas mãos e outras partes do corpo com brasas ou cigarro. Levava golpes na cara e nos seios. Durante os 48 dias que esteve nessas instalações, recebeu a visita do Comissário Geral Alberto Cantero, exigindo que ela assinasse uma suposta declaração. Diante de sua negativa, as torturas físicas e psicológica continuaram. Ela era ameaçada constantemente de morte e diziam que iriam sequestrar seus irmãos e trazê-los para serem torturados. Seu corpo estava coberto de picadas de formigas. No dia 3 de abril foi levada encapuzada até um calabouço e mantida lá até o dia 27 de maio. Ali ela sofreu várias ameaças de novas torturas.

Diante dessa situação de incerteza, ela se viu obrigada a realizar uma greve de fome por dez dias, reclamando que fosse transferida para outro lugar, onde pudesse exercer seu direito de defesa e réplica das acusações da polícia. No dia 28 de maio ela foi transferida para a Guarda de Segurança, onde permaneceu também incomunicada.

As consequências das torturas físicas e psicológicas que sofreu são inúmeras: alucinações visuais e auditivas, transtornos motores, fortes dores de cabeça e na coluna vertebral, adormecimento do corpo, taquicardia, problemas de pressão arterial entre outros ${ }^{17}$.

Outro caso de mulher que foi detida grávida foi o de Celsa Ramirez, cujos registros de sua detenção encontram-se nos Arquivos do Terror. Durante seu interrogatório ela sofreu sangramentos, levando-a acreditar que houvesse perdido seu filho. Contudo, apesar das torturas sofridas, conseguiu manter a gravidez. Seu filho Derlis Miguel Ramírez nasceu no hospital Rigoberto Caballero em 29 de novembro de 1975. Posteriormente ao

\footnotetext{
${ }^{17}$ Informações retiradas de registros documentados nos Arquivos do Terror, localizado no Centro de Documentación y Archivo para la Defensa de los Derechos Humanos (CDyA) da Corte Suprema de Justiça do Paraguai.
} 
nascimento, ambos foram detidos novamente no centro de detenção Fernando de Mora. Ficaram presos até o dia 10 de agosto de $1978^{18}$.

Em seu testemunho dado à Comissão da Verdade e Justiça do Paraguai, ele diz não se recordar muito do tempo que passou na prisão. Ele só ficou sabendo da história de seus pais aos 8 anos de idade, quando sua mãe lhe contou a história de seu pai biológico. Segundo relato de sua mãe, seu nascimento pode ser considerado um milagre, devido as torturas sofridas enquanto esteve presa. Contudo, o medo do retorno daqueles dias de repressão e tortura ainda permanece entre eles. Até hoje sua mãe ressalta a importância de se ter documentos de outros países para poder se refugiar, caso aqueles tempos sombrios voltem a acontecer. Além disso, eles tem dificuldade de realizar projetos futuros, a planejar suas vidas à longo prazo. O depoimento a seguir elucida essa informação.

Si pudimos llegar a eso es que puede volver a suceder, entonces el futuro se vuelve incierto si hay alguna represión y hay que escaparse. Mamá hasta ahora insiste que tenemos que tener documentos de otros países, se instala ese miedo permanente, es difícil imaginar proyectos de futuro y costó bastante tener proyectos a largo plazo como familia, porque era siempre la posibilidad que se desatara de vuelta una represión, tener mucha paranoia. Pero yo siento, sobre todo ahora, con este nuevo escenario que esas heridas se pueden ir curando ${ }^{19}$.

Há sempre o medo do retorno da repressão na medida em que os agentes do terror não foram punidos ou presos, permanecem desfrutando de privilégios e favores garantidos pelo Partido Colorado e pela estrutura política montada no stronismo. Essa situação assemelha-se a uma situação de permanente guerra civil, onde a impunidade dos agentes da repressão e do Estado alimentam um medo paranóico em suas vítimas. Para Dermis Miguel Ramírez, a história do Paraguai é repleta de violência e ódio, sobretudo durante os anos da ditadura militar. Mas a maior violência sofrida pela sociedade paraguaia é a criminalização e demonização de um grupo social, baseadas em mentiras inventadas pelo Estado que procurava justificar a usurpação do direito legítimo de reivindicação e de luta por uma sociedade mais democrática.

Além dos casos de detenção e prisão por motivos políticos de crianças paraguaias, como pode ser verificado em vários registros documentados nos Arquivos do Terror, havia ainda casos de sequestro de crianças e posterior adoção das mesmas por agentes da repressão ou por pessoas ligadas ao sistema repressivo. Os casos das crianças argentinas Carolina Susana e Pablo Hernán Bianco Wehrli encontradas no Paraguai ilustram esses fatos.

A história do desaparecimento de Carolina Susana e Pablo Hernan começou em setembro de 1984, quando a organização da Abuelas de Plaza de Mayo recebeu uma denúncia de Carolina Giménez, tia de Norma Tato. Segundo a denúncia, Norma Tato foi sequestrada em sua casa, em Buenos Aires, na madrugada de 13 de

\footnotetext{
${ }^{18}$ Dossiê de Celsa Ramírez Rodas, entrevista concedida à Comisíon de Verdade y Justicia do Paraguai no dia 17 de agosto de 2008.

${ }^{19}$ Dossiê de Dermis Miguel Ramírez, entrevista concedida à Comisíon de Verdade y Justicia do Paraguai no dia 11 de agosto de 2008.
} 
abril de 1977 pelas forças de segurança da Argentina. Naquela época ela vivia com seus dois fillhos Sebastian e Mattias e esperava um terceiro, filho de seu atual companheiro Jorge Casariego, cujo nascimento estava previsto para agosto do mesmo ano.

A associação das Abuelas iniciou uma investigação sobre o paradeiro do casal e de seu filho, nascido em cativeiro, através de testemunhos de outros presos políticos que tinham sido libertados do Campo de Mayo, também conhecido como "El Campito", onde o casal foi visto e onde ocorreu o nascimento do seu filho. Segundo testemunho Norma deu à luz em condições precárias, em um pequeno quarto, ao lado do pavilhão 1, sem assistência médica. Ela ficou poucas horas junto de seu filho, quando ela e seu companheiro foram separados. Até hoje não se tem notícia do paradeiro de Jorge Casariego.

Paralelo a essas investigações, a organização das Abuelas de la Praza de Mayo recebeu denúncias anônimas de duas crianças desaparecidas que estariam sendo criadas pelo Major médico do Exército argentino Noberto Atilio Bianco e sua esposa Nilda Susana Wehrli. A existência de registros de que o casal não poderia ter filhos causou extranhamento na organização. Bianco trabalhou no Hospital Militar durante sete anos, atuou como médico no Campo de Mayo e estava no comando da maternidade clandestina. Ele foi responsável pela distribuição de vários bebês de ativistas políticas detidas grávidas que foram executadas após os nascimentos de seus filhos ou separadas definitivamente de seus filhos. Vários testemunhos disseram que Bianco fazia o parto das ativistas grávidas, vítimas de desaparecimento forçado, e retirava-lhes os recém-nascidos para serem encaminhados para adoção. Depois de realizar o parto dessas crianças, os agentes da repressão, normalmente médicos ligados ao sistema repressivo, injetavam-lhes uma injeção que impossibilitavam de amamentar seus filhos (CALVEIRO, 2013).

Em 1985, a organização das Abuelas de Plaza de Mayo entraram com uma ação no Juizado Federal N. 1 de San Isidro. Em 1986, diante do processo que estava sendo movido contra ele, Bianco, sua esposa e seus dois filhos se refugiam no Paraguay, com identidades falsas. Em 1987, o casal e seus filhos foram localizados em Assunção (Paraguai). No ano seguinte, a justiça argentina determinou a prisão do casal por considerar as evidências do sequestro suficientemente fortes. Eles foram acusados de detenção e ocultamento de menores por dez anos, supressão do estado civil das crianças e falsificação de documentos públicos. Na época do processo penal, em 23 de abril de 1987, foi solicitado a extradição dos dois acusados e retorno das crianças para verificação da identidade biológica. Após um longo processo administrativo e com a intervenção da Comissão Interamericana de Direitos Humanos, no dia 7 de março de 1997, o casal Bianco e Wehrli foram entregues à justiça argentina (ABUELAS, 1997).

Durante muitos anos, as Abuelas de Plaza de Mayo realizaram várias diligências junto as autoridades da Argentina e do Paraguai para acelerar os processos judiciais e obter amostras de sangue das crianças a fim de 
compará-las com as da suposta família biológica. A abordagem dos jovens foi feita através de uma neta dos pais biológicos que foi submetida ao exame de sangue, sem qualquer intervenção judicial, em um laboratório particular. A comparação das amostras atestaram que Pablo Hernán Bianco correspondia ao grupo familiar Casariego e Tato. O comunicado oficial do resultado da análise aconteceu somente em 30 de novembro de 2006.

Desde o seu nascimento e sequestro até o reconhecimento oficial do Tribunal Federal de San Isidro sobre a origem da sua paternidade biológica passaram-se vinte e nove anos de mentiras, omissões, usurpação de direitos civis e familiares. Foram décadas de impedimentos de relações fraternas, mas, sobretudo, de incertezas e angústias quanto ao paradeiro de Pablo Hernán.

\section{CONSIDERAÇÕES FINAIS}

O sequestro e o desaparecimento forçado configuram-se como crimes de lesa humanidade e são, portanto, imprescritível. O sofrimento dos familiares de desaparecidos é uma dor que não termina nunca. Ela está presente na busca incansável por informaçoes, no vazio deixado pela ausência do ente querido e pelos momentos de convivência usurpados, mas principalmente, nas identidades roubadas e nas vidas ceifadas.

A memória desses fatos, explícita nos testemunhos dos sobreviventes dos centros clandestinos de detenção e dos familiares de desaparecidos políticos, é composta de vazios, traumas, cheiros, imagens e agressões que insistem em se fazerem presentes. As lembranças pertencem as pessoas e o que é lembrado está amparado pela sociedade, pela cultura, pelos discursos oficiais e públicos (SARLO, 2007).

A história silenciada pelos porões da ditadura, na intimidade do medo e nas lacunas da memória, vem encontrando formas peculiares de se manifestar nas diferentes realidades sociais. A configuração dessas lembranças, embora descontínua e fragmentada, torna-se inesgotável.

Os documentos registrados nos Arquivos do Terror e descobertos em 1992 contribuiram para o resgate dessas identidades e para reconstrução dessas vidas. Seus registros ajudaram a levantar provas e evidências de crimes imprescritíveis e de violações dos direitos humanos de milhares de pessoas que, até o seu descobrimento, eram sistematicamente negados pelo Estado.

A análise dessa documentação tornou possível uma reavaliação das funções de suas fontes. Se durante o momento de criação dos documentos o objetivo era registrar as detenções e prisões daqueles que "ameaçavam a segurança nacional", bem como as ações do Estado para eliminar essa ameaça, atualmente esses documentos têm sido utilizados para comprovar as violações dos direitos humanos cometidas pelos agentes da segurança em nome do Estado ditatorial.

A análise dos prontuários dos detidos, das declarações indagatórias, dos informes sobre pessoas procuradas, sobre reuniões, atividades sociais, estudantis e sindicais, memorandos solicitando informações sobre 
elementos subversivos procurados pela junta militar argentina e uruguaia, informes de entrada e saída de pessoas nas fronteiras, de informações obtidas durante os interrogatórios possibilitou o resgate de histórias de violações dos direitos humanos ocorridas no Cone Sul e no Brasil, bem como a natureza ditatorial dos regimes militares instalados. A análise dessa documentação permitiu que uma parte oculta da história paraguaia, chilena, argentina, uruguaia e brasileira viesse a público. As fontes oriundas dos Arquivos do Terror, criadas pelas mãos dos próprios agentes da repressão, seguros de sua impunidade, tornaram possível a abertura e revisão de processos judiciais movidos contra o Estado paraguaio pela violação dos direitos humanos de milhares de cidadãos.

Nesse sentido, estudar seus documentos é ajudar a recuperar parte da história recente do Paraguai, mas, sobretudo é recontar outra história, uma história de resistência e luta pela democracia, uma história de impunidades, delações e de personalismo político, uma história de medo e subserviência, uma história de sofrimento, morte e luto. Trabalhar essa memória e reconstituir essa história é possibilitar aos paraguaios repensar seus valores atuais com base em realidades vividas e sofridas, é oferecer razões para ações presentes e escolhas futuras, é permitir um repensar dos deveres e dos direitos do cidadão numa democracia baseada em favores e privilégios políticos, sociais e econômicos.

A atuação de entidades de direitos humanos como as associações das Madres e Abuelas de Plaza de Mayo, dos familiares de mortos e desaparecidos políticos, assim como de advogados que ousaram defender os direitos dos presos e refugiados políticos como o advogado Martín Almada foi fundamental nas denúncias dos casos de violações dos direitos humanos pelos governos militares argentinos, paraguaios, chilenos, uruguaios e brasileiros. Suas ações foram fundamentais para enfraquecer o arbítrio dos governantes e interromper o terrorismo de estado vigente nestes países.

A imposição de limites aos laços familiares, às manifestações fraternais, à liberdade de pensamento encontra entraves que subvertem a história oficial. Memórias são silenciadas, vidas foram eliminadas, mas os registros dos fatos não podem ser apagados. Eles permanecem explícitos nos documentos encontrados em arquivos como os Arquivos do Terror do Paraguai e em vários outros arquivos no Cone Sul e no Brasil, que preservam fontes documentais oficiais produzidas pelos estados ditatoriais. A análise desses acervos e dos depoimentos prestados pelas vítimas dos regimes e familiares de desaparecidos políticos nos possibilitou contrapor versões e problematizar a veracidade das informações contidas nestes documentos

Contudo, o resgate desses fatos ainda é limitado ao acesso às fontes, às evidências, aos documentos e aos testemunhos. O relato e análise dos casos de sequestro, tortura, execução e apropriação de crianças durante a vigência dos estados ditatoriais na América do Sul estão vinculados às leis de acesso à informação dos países em questão. Além disso, a memória desse passado recente e traumático é composta de vácuos de registros e evidências que foram eliminados, sobretudo após o término dos regimes ditatoriais. 
O resgate dessa história através das fontes arquivistas tem permitido às gerações passadas reconstituírem suas histórias, preenchendo as lacunas da memória subjetiva que insiste em se tornar coletiva, porém sob o ângulo da objetividade histórica. A importância do relato desses fatos está em possibilitar às gerações atuais e futuras o direito à memória e ao conhecimento de acontecimentos omitidos pela história oficial, a possibilidade de reconstituir antigas lembranças solapadas pela perseguição política, pelo trauma da tortura, pelo desaparecimento forçado. O resgate dessa história, a partir da análise dos acervos estudados nesta pesquisa e de outros semelhantes permite às gerações presentes e futuras o conhecimento do nosso passado recente, com a recuperação de fatos históricos relacionados às violações de direitos humanos de milhares de pessoas, e a assimilação de suas lições, para que nunca mais se esqueça, para que nunca mais se repita.

\title{
TERROR ARCHIVES AND STRONISMO: MEMORY, HISTORY AND LUTE
}

\begin{abstract}
The objective of this study was to analyze the importance of "Terror Archives" stored in the Center for Documentation and Archives, located in the Supreme Court of Justice of Paraguay. This Center was created to store information connected to the Defense of Human Rights (CDyA), so to rescue the historical memory of "stronismo" and to the knowledge of cases of kidnapping, imprisonment and torture of children and adolescents during the Paraguayan dictatorship of General Alfredo Stroessner. The methodology was the bibliographical and documentary research, the last was based on the investigation of sources and evidence from diverse backgrounds: official documents, military documents and testimony from victims and relatives of missing persons provided by the Commission de Verdad y Justicia Paraguay. The central argument of this research consists in the assertion that the Terror Archives, containing systematic records of cases of human rights violations in Paraguay and the Southern Cone, contributed to the rescue of the historical memory of the Paraguayan dictatorship period. The analysis of this documentation allowed reconstruct the memory of the recent past whose memories and testimonies were constantly challenged in court.
\end{abstract}

Keywords: Stronismo. Human Rights. Terror Archives. Memory. History.

\section{REFERENCIAS BIBLIOGRÁFICAS}

ABUELAS DE PLAZA DE MAYO. Restitución de niños. 1997. Disponível em: http://www.pparg.org/pparg/documentos/represion/ana_apropiacion/_b/contentFiles/RESTIT UCION_DE_NINOS.pdf. Acesso em: 11 fev. 2014.

ALMADA, Martín. Paraguay la cárcel olvidada: el país exiliado. 14 ed. Asunción: Marben, 2013.

ALVAREZ, Mario Rubén. Data Feliz no Paraguai: festejos de 3 de novembro, aniversário de Alfredo Stroessner. In: ROLLEMBERG, Denise; QUADRAT, Samantha (Orgs.). A construção social dos regimes autoritários: Brasil e América Latina. Rio de Janeiro: Civilização Brasileira, 2010. V.II. 
AMARAL, Raúl. Los presidentes del Paraguay: Cronica política (1844-1954). Tomo 1. Assunción: Servilibro, 2005.

ANGUITA, Eduardo. Sano Juicio, Baltasar Garzón, algunos sobrevivientes y la lucha contra la impunidad de Latinoamérica. Buenos Aires: Editorial Sudamericana, 2001.

ARDITI, Benjamin. Adiós a Stroessner: a reconstrución política del Paraguay. Assunção: CDE, RP Editores, 1992.

CALVEIRO, Pilar. Poder e Desaparecimento: os campos de concentração na Argentina. Trad. Fernando Correa Prado. São Paulo: Boitempo, 2013

COMISIÓN DE VERDAD Y JUSTICIA. Informe Final: anive haguã oiko. Assunción: Comissión de Verdad y Justicia, 2008. Tomo V.

Informe Final: documentos suplementarios. Assunción: Comissión de Verdad y Justicia, 2008. Tomo VIII. Parte III.

CONADEP. Nunca mais: Informe da Comissão Nacional sobre o desaparecimento de pessoas na Argentina. Porto Alegre: L\&PM, 1986.

DINGES, John. Os anos do Condor: uma década de terrorismo internacional no Cone Sul. São Paulo: Cia das Letras, 2005.

HUNT. Lynn. A invenção dos direitos humanos; uma história. São Paulo: Companhia das Letras. 2009

JELIN, Elizabeth. Los trabajos de la memoria. Madrid: Siglo Veintiuno, 2002.

LÓPEZ, Miguel H. Stroessner e Eu: a cumplicidade social com a ditadura (1954-1989). In: ROLLEMBERG, Denise; QUADRAT, Samanta (Orgs.). A Construção Social dos Regimes Autoritários: legitimidade, consenso e consentimento no século XX - Brasil e América Latina. São Paulo: Civilização Brasileira, 2010. p.437- 470.

MERLINO, Tatiana; OJEDA, Igor (Orgs). Direito à memória e à verdade: Luta, substantivo feminino. São Paulo: Caros Amigos, 2010.

PAZ, Alfredo Boccia. Los "Archivo del horror" del Paraguay: los papeles que resignificaron la memoria del stronismmo. In: FICO, Carlos; FERREIRA, Marieta de Moraes; ARAÚJO, Maria Paula; QUADRAT, Samantha Vaz (Orgs.). Ditadura e Democracia na América Latina: balanço histórico e perspectivas. Rio de Janeiro: FGV, 2008. P. 27-43.

PAZ, Alfredo Boccia; AGUILAR, Paz Rosa Palau; SALERNO, Osvaldo. Paraguay - os Arquivos del Terror: Los papeles que resignificaron la memoria del stronismo. Asunción: Corte Suprema de Justicia, 2008.

PAZ, Alfredo BOCCIA; GONZÁLEZ, Myriam; AGUILAR, Rosa Palau. Es mi informe: Los archivos secretos de la Policía de Stroessner. Asunción: Centro de Documentación y Estudios, 1994.

PEREIRA, Anthony W. Ditadura e Repressão: o autoritarismo e o estado de direito no Brasil, no Chile e na Argentina. São Paulo: Paz e Terra, 2010. 
ROLLEMBERG, Denise; QUADRAT, Samanta (Orgs.). A Construção Social dos Regimes Autoritários: legitimidade, consenso e consentimento no século XX - Brasil e América Latina. São Paulo: Civilização Brasileira, 2010.

SÁ, C. P. A memória histórica numa perspectiva psicossocial. Morpheus - Revista Eletrônica em Ciências Humanas, 9 (14), p.91-100.2009.

SARLET, Ingo Wolfgang. A eficácia dos direitos fundamentais: uma teoria geral dos direitos fundamentais na perspectiva constitucional. 10. ed. Porto Alegre: Livraria do Advogado Editora, 2009.

SARLO, Beatriz. Tempo passado: cultura da memória e guinada subjetiva. Trad. Rosa Freire d' Aguiar. São Paulo: Companhia das Letras; Belo Horizonte: UFMG, 2007

VERA, Myrin González. "Data Feliz” no Paraguai: festejos de 3 de novembro, aniversário de Alfredo Stroessner. In: ROLLEMBERG, Denise; QUADRAT, Samanta (Orgs.). A Construção Social dos Regimes Autoritários: legitimidade, consenso e consentimento no século XX - Brasil e América Latina. São Paulo: Civilização Brasileira, 2010.p. 393-436.

Trabalho enviado em 14 de agosto de 2015.

Aceito em 12 de outubro de 2015. 